\title{
Seawater-Neutralized Bauxite Residue-Polyester Composites as Insulating Construction Materials
}

\author{
Maissa Adi, Basim Abu-Jdayil *D, Fatima Al Ghaferi, Sara Al Yahyaee and Maryam Al Jabri \\ Chemical \& Petroleum Engineering Department, UAE University, P.O. Box 15551, Al Ain 15551, UAE; \\ 201150553@uaeu.ac.ae (M.A.); 201202787@uaeu.ac.ae (F.A.G.); 201101752@uaeu.ac.ae (S.A.Y.); \\ 201150011@uaeu.ac.ae (M.A.J.) \\ * Correspondence: babujdayil@uaeu.ac.ae
}

Citation: Adi, M.; Abu-Jdayil, B.; Al Ghaferi, F.; Al Yahyaee, S.; Al Jabri, M. Seawater-Neutralized Bauxite Residue-Polyester Composites as Insulating Construction Materials. Buildings 2021, 11, 20. https://doi. org/10.3390/buildings11010020

Received: 21 November 2020 Accepted: 28 December 2020 Published: 6 January 2021

Publisher's Note: MDPI stays neutral with regard to jurisdictional clai$\mathrm{ms}$ in published maps and institutional affiliations.

Copyright: $(2021$ by the authors. Licensee MDPI, Basel, Switzerland. This article is an open access article distributed under the terms and conditions of the Creative Commons Attribution (CC BY) license (https:// creativecommons.org/licenses/by/ $4.0 /)$.

\begin{abstract}
Bauxite residue (BR) is one of the most commonly generated industrial wastes in the world. Thus, novel techniques for its proper utilization must be urgently developed. Herein, seawater-neutralized BR-unsaturated polyester resin (UPR) composites are presented as insulating construction materials with promising mechanical performance. Composites with different BR content ( $0-60 \mathrm{vol} . \%)$ were prepared to evaluate the influence of BR content on the compressive, tensile, and flexural strengths as well as the moduli of BR-UPR composites. Experimental results revealed that adding BR particles to the polyester matrix increased the compressive properties (strength, modulus, and strain). The composites containing 20 vol.\% BR showed the maximum compressive strength $(108 \mathrm{MPa})$, while the composites with 30 vol.\% BR exhibited the maximum compressive modulus (1 GPa). Moreover, the reduction in tensile and flexural strengths with an increase in the BR content may be attributed to the lower efficiency of stress transfer between the BR particle-polyester interface due to weak adhesion at the interface, direct contact between particles, and presence of voids or porosity. Although the tensile strength and failure stress decreased with increasing filler content, the produced composites showed outstanding tensile strength (4.0-19.3 MPa) compared with conventional insulating materials. In addition, the composite with $40 \mathrm{vol} \% \mathrm{BR}$ demonstrated a flexural strength of $15.5 \mathrm{MPa}$. Overall, BR-UPR composites showed excellent compatibility with promising mechanical properties as potential insulating construction materials.
\end{abstract}

Keywords: bauxite residue; unsaturated polyester; solid waste; mechanical behavior; construction composite

\section{Introduction}

Exploring recycling alternatives is highly desired for industrial waste management. Several recycling procedures have been adopted through legislation or as a means of eliminating disposal costs and avoiding soil and water pollution. Recycling waste materials is an environmentally friendly step in the construction industry, where they can be reused as raw materials in engineering applications. Industrial waste often involves mostly inorganic ingredients, such as silicon, aluminum, calcium, and iron oxides, which are suitable for reuse in various applications [1].

Bauxite residue (BR) is a solid waste byproduct of the Bayer process of alumina production by alkaline extraction from bauxite ore [2]. Aluminum hydroxide precipitation from a pregnant sodium aluminate solution is described by the Bayer process, which involves the hydrothermal digestion of bauxite with caustic soda. To produce a sodium aluminate solution, aluminum hydroxides in bauxite are dissolved in $\mathrm{NaOH}[3,4]$. BR is the residue formed by the insoluble fraction of bauxite and can be separated from the sodium aluminate solution using thickeners, filters, or a pressure decanter. BR is further thickened, washed, and filtered to recover alkalinity and the sodium aluminate used in the Bayer cycle to rise the solid residue fraction after aluminate solution is cooled down and seeded for the production of aluminum hydroxides [3]. BR contains five main oxides, i.e., $\mathrm{SiO}_{2}, \mathrm{Fe}_{2} \mathrm{O}_{3}$, 
$\mathrm{Al}_{2} \mathrm{O}_{3}, \mathrm{TiO}_{2}$, and $\mathrm{Na}_{2} \mathrm{O}$, although the composition of $\mathrm{BR}$ can vary based on the bauxite source [5-7].

BR is strongly alkaline and involves high costs and requires vast landfills for disposal when its $\mathrm{pH}$ between 10.5 and 12.5 [3,5]. The annual worldwide production of BR is approximately $120 \mathrm{Mt}$ [5]. Furthermore, the treated amount of bauxite that ends up as waste is approximately $35-40 \%$ per ton. In the coming years, this value is expected to increase owing to increasing aluminum demand, which, in turn, will increase BR generation. Moreover, BR is disposed in landfills and stored in large lagoon-like impoundments in the long term [8]. Consequently, the inappropriate disposal of BR results in severe soil contamination that severely impairs soil fertility. In addition, it can lead to groundwater pollution, which negatively affects living organisms $[9,10]$. Therefore, BR raises environmental risks and is not economically sustainable owing to increasing accumulation. Therefore, the development of novel techniques for the proper storage, disposal, and utilization of BR is urgently required.

Utilization of BR can provide various benefits in the production of building materials. Using recycled BR in building materials can valorize this waste. Moreover, the demand for building materials with high environmental performance has increased in the construction industry. The two leading sustainable construction accreditation schemes, i.e., Building Research Establishment Environmental Assessment Method and Leadership in Energy and Environmental Design, require reducing the life cycle environmental impact of construction materials and increasing the use of recycled materials for construction [11]. The application of $\mathrm{BR}$ as raw materials in the construction industry fulfills these requirements. At a higher level, an EU-wide circular economy action plan proposed by the European Commission stresses the importance of getting secondary raw materials fed back into the economy and commits to formulating innovative industrial processes in which the waste generated in one industry is reused in another [12].

Modern materials can be developed to effectively contribute to BR management. For example, BR can be applied to composite fabrication to mitigate its environmental impact. Thus, cleaner production, sustainable development, and environmental safety can be accomplished [8]. Polymer composites fabricated using filler reinforcements are encouraging alternatives to conventional construction materials. Applying industrial wastes as fillers in polymer composites contributes to industrial waste management [13]. BR has been applied as a reinforcement filler in several material systems, such as in metal matrix fabrication [14], self-compacting concrete [15], geopolymer fabrication [16], and hybrid polymer composites [17]. These studies illustrate that considerable research has been conducted for evaluating the application prospects of BR [8].

However, there are a limited number of investigations showing that the addition of BR as a filler in polymer composites can improve their mechanical performance. Vigneshwaran et al. [8] showed that the increase in BR content (up to 20\%) increases the tensile and impact strengths of a hybrid composite fabricated using BR as a filler and sisal fiber as the reinforcement in a polyester matrix. The composite demonstrated excellent resistance against crack development and propagation under tensile and impact loadings. Another study revealed that the addition of $\mathrm{BR}$ along with sisal and banana fiber-reinforced polyester composite enhanced impact and flexural strength, making it suitable for applications that require high load-bearing capacity [18]. An investigation by Ganeshan et al. [19] showed that the addition of BR to natural fiber-polyester composite considerably increased the flexural strengths of the polyester composites while decreasing their tensile strengths. In addition, the flexural strength of coir polyester composites increased upon addition of BR to a certain limit and then decreased [20].

This work aims to evaluate the utilization of the seawater-neutralized BR in the development of composite materials that can be used for thermal insulation and in construction applications. We have investigated the physical and thermal characteristics of seawater-neutralized BR-unsaturated polyester resin (BR-UPR) composites in our previous studies [21]. Due to the promising results obtained therein (Table 1), in this work, 
we aimed to study the mechanical properties of the developed BR-UPR composites. The successful production of the BR-based insulating materials will serve as a gateway for the utilization of the millions of tons of toxic waste available worldwide. Compared with other composites, the BR composites can be used as a thermal insulation material with promising mechanical properties, which is one of the main drawbacks associated with the traditional thermal insulators.

Table 1. Thermal and physical characteristics of bauxite residue (BR)-unsaturated polyester resin (UPR) composites.

\begin{tabular}{cccc}
\hline Characteristics. & UPR & BR-UPR Composite (20\%) & BR-UPR Composite (40\%) \\
\hline Bulk density $\rho\left(\mathrm{kg} / \mathrm{m}^{3}\right)$ & 1200 & 1261 & 1484 \\
Thermal conductivity $\mathrm{k}(\mathrm{W} /(\mathrm{m} \cdot \mathrm{K}))$ & 0.098 & 0.082 & 0.096 \\
Thermal diffusivity, $\alpha\left(\mathrm{mm}^{2} / \mathrm{s}\right)$ & - & 0.272 & 0.161 \\
24 h water retention @ $25^{\circ} \mathrm{C}(\mathrm{wt} . \%)$ & 0.024 & 0.101 & 0.118 \\
Overall weight change $(\%)$ upon thermal load & 99.85 & 93.32 & 59.33 \\
\hline
\end{tabular}

\section{Materials and Methods}

\subsection{Material}

Seawater-neutralized BR with particle size $<300 \mu \mathrm{m}$ (Figure 1) was obtained from Virotec Global Solutions (Arundel, Australia). It is commercially known as Bauxsol ${ }^{\mathrm{TM}}$, which is produced by treating the alkaline residue of the Bayer process with seawater, resulting in the conversion of soluble hydroxides and carbonates into less-soluble layered hydroxides, carbonates and hydroxyl carbonates of the base metals and producing a less-alkaline liquor that can be safely utilized.

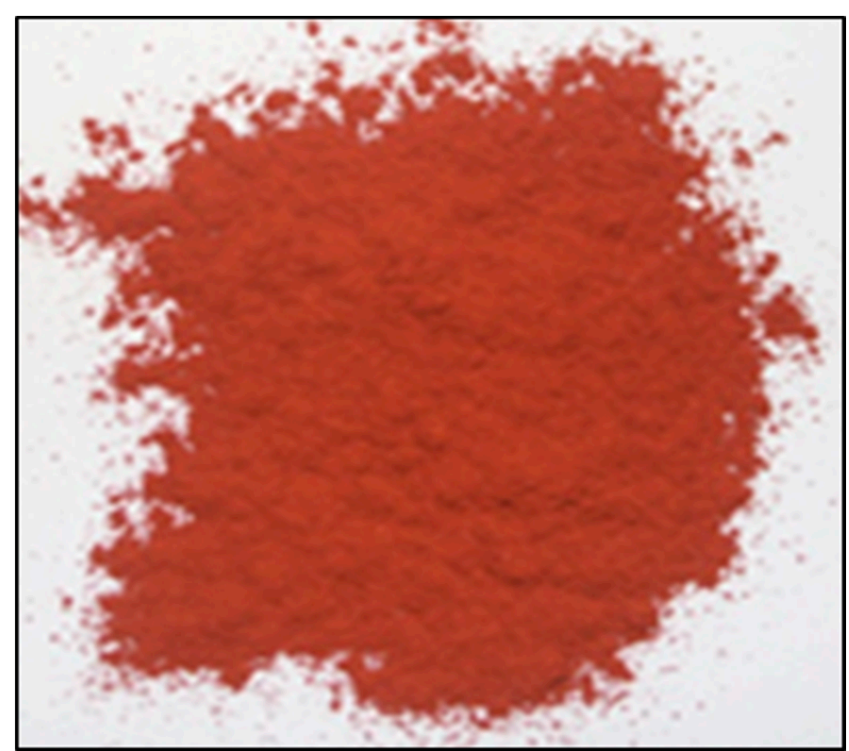

(a)

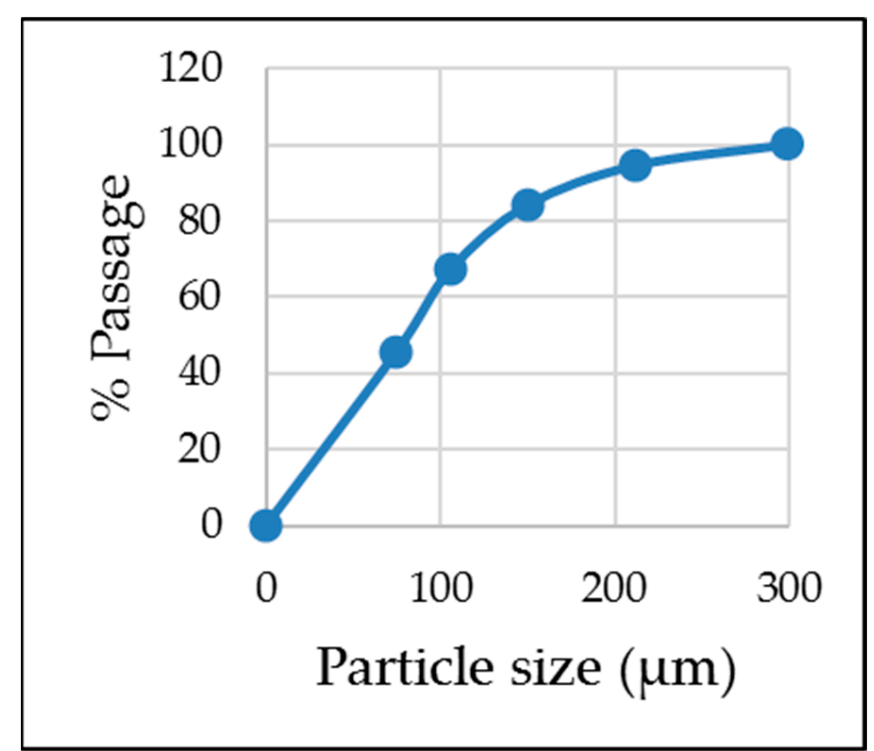

(b)

Figure 1. (a) Seawater-neutralized bauxite residue (BR); (b) particle distribution of BR.

The polyester, i.e., methyl ethyl ketone peroxide (MEKP), was obtained from Reichhold Norpol Company, Dubai (UAE). Special characteristics of the polyester used in this study include low water absorption, low cost, rapid curing with no gases evolved, and ease of handling.

\subsection{Composite Fabrication}

BR-UPR composites with various BR contents ( $0-60$ vol.\%) were produced at room temperature using a high-viscosity mixer, see Table 2 . The mixing conditions were as follows. A particular amount of BR was gradually added to the polyester mixture, and 
when the mixture became homogenous (after approximately $5 \mathrm{~min}$ ), MEKP was added to the mixture for the thermosetting process. While the mixture was being prepared, the inner surface of three types of stainless-steel molds was coated with paraffin wax and polyvinyl acetate to prevent the sample from sticking to the mold. After that, the mixture was poured into the molds, which had specific shapes and sizes based on the ASTM standards to perform compression, tensile, and flexural strength tests on the prepared composites. Figure 2 illustrates the procedure of composite fabrication. The dumbbell-shaped tensile specimen had a total length of $100 \mathrm{~mm}$, gauge length of $30 \mathrm{~mm}$, and thickness of $4 \mathrm{~mm}$, while the flexural specimen had a length of $75 \mathrm{~mm}$, width of $14 \mathrm{~mm}$, and thickness of 4 $\mathrm{mm}$ (Figure 3). Three to six specimens of each BR content were fabricated. The produced specimens were then tested for compressive, tensile, and flexural strengths according to ASTM D695-15, ASTM D638-14, and ASTM D790 specifications, respectively.

Table 2. Mix proportion of BR-UPR composites.

\begin{tabular}{ccc}
\hline BR-UPR Composite & BR Content (vol.\%) & UPR Content (vol.\%) \\
\hline Pure polyester & 0 & 100 \\
10 vol.\% BR & 10 & 90 \\
20 vol.\% BR & 20 & 80 \\
30 vol.\% BR & 30 & 70 \\
40 vol.\% BR & 40 & 60 \\
50 vol.\% BR & 50 & 50 \\
60 vol.\% BR & 60 & 40 \\
\hline
\end{tabular}

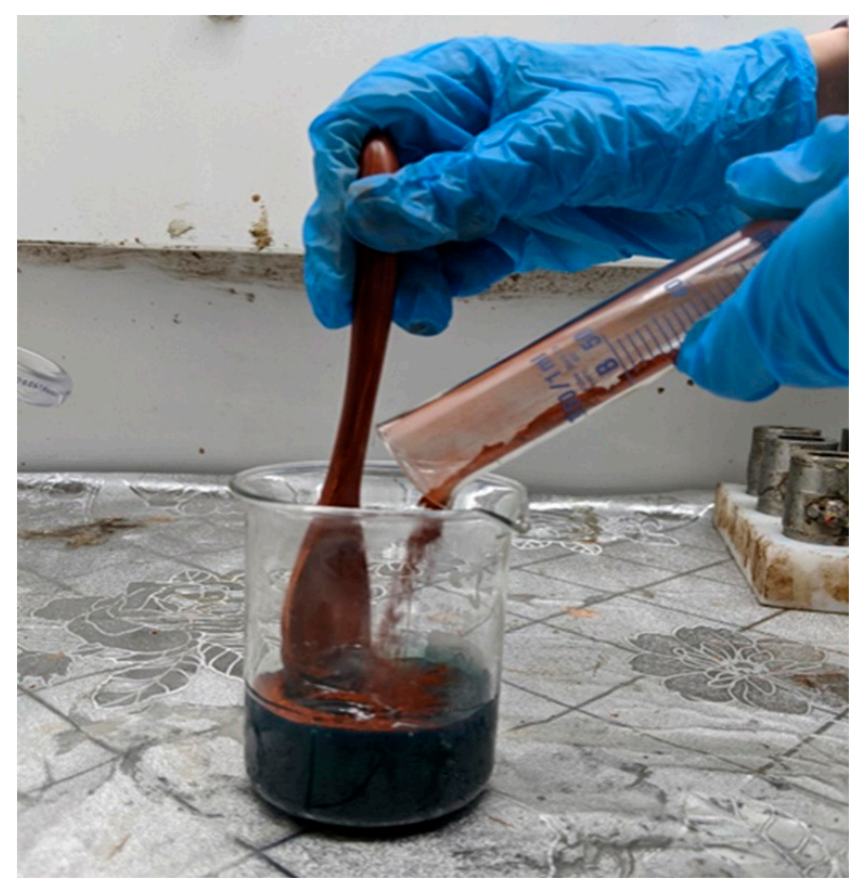

(a)

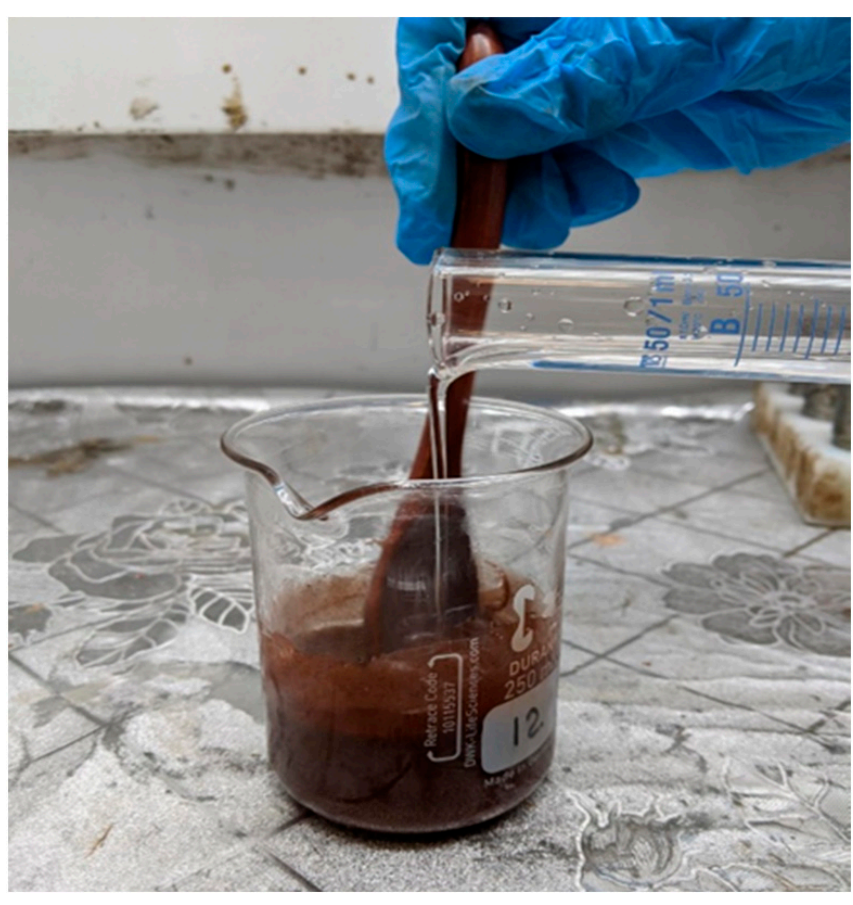

(b)

Figure 2. Cont. 


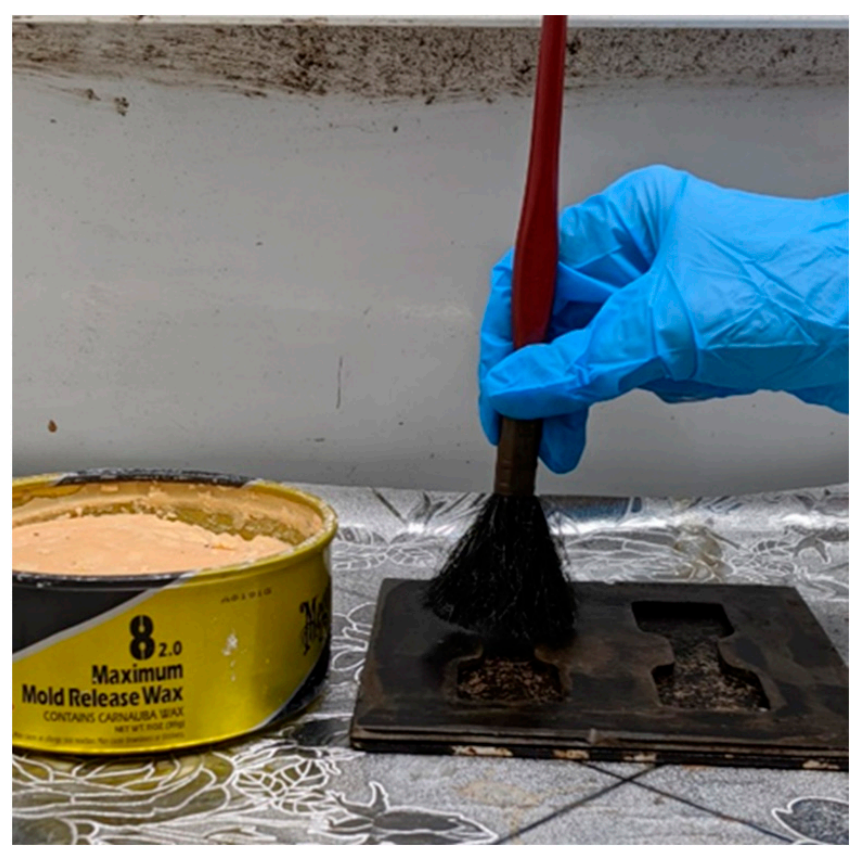

(c)

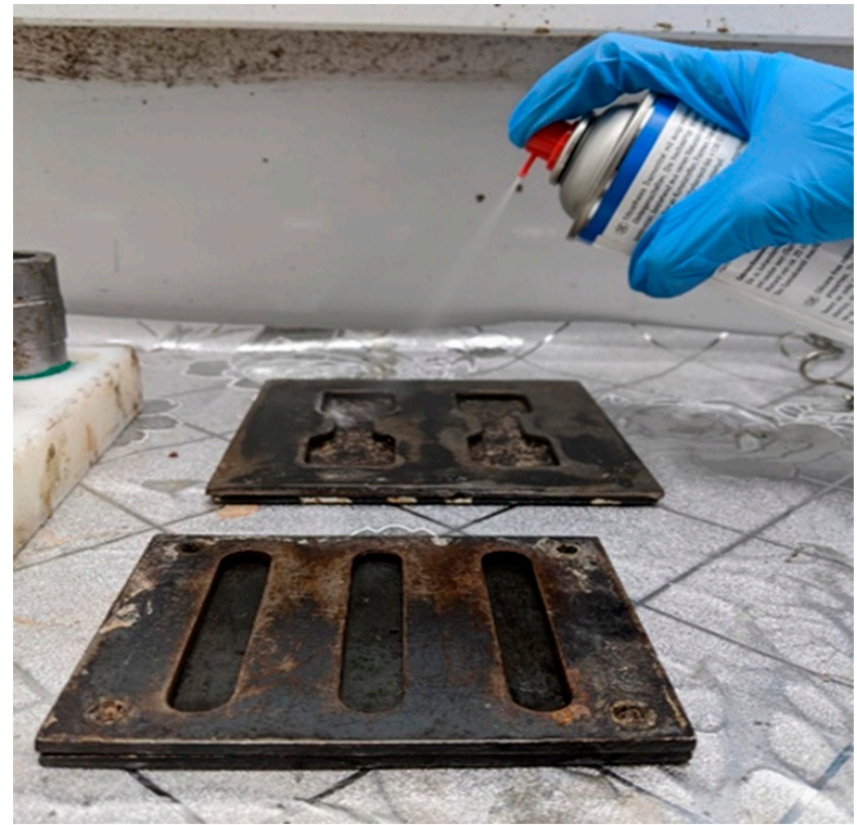

(d)

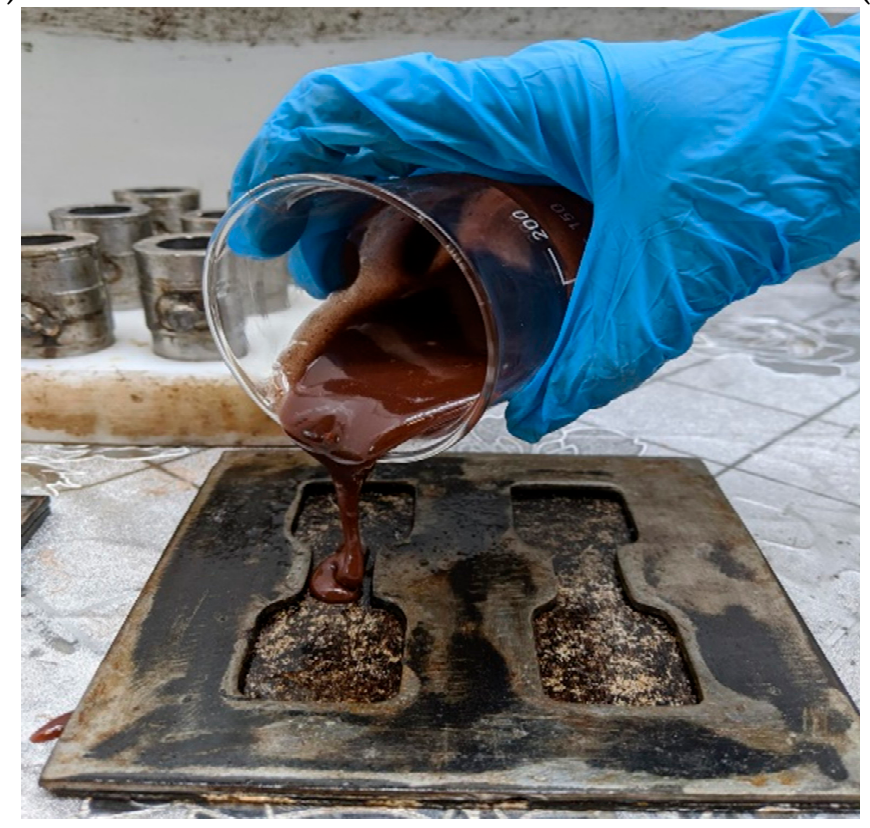

(e)

Figure 2. (a) A particular amount of BR was gradually added to the UPR resin; (b) when the mixture became homogenous (after approximately $5 \mathrm{~min}$ ), MEKP was added to the mixture for the thermosetting process (c) the inner surface of three types of stainless-steel molds was coated with paraffin wax (d) and polyvinyl acetate to prevent the sample from sticking to the mold; (e) the mixture was poured into the molds. 


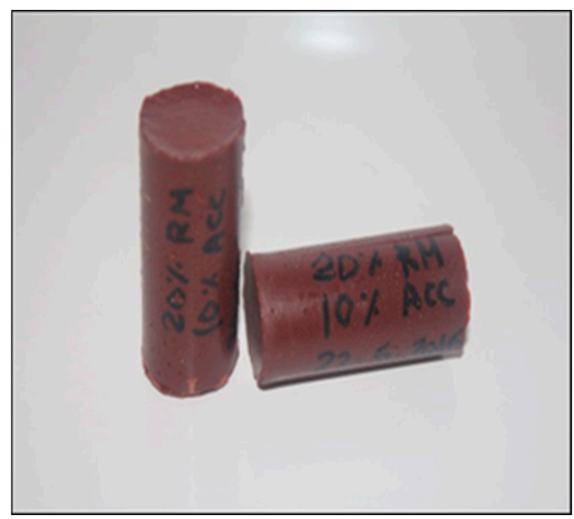

(a)

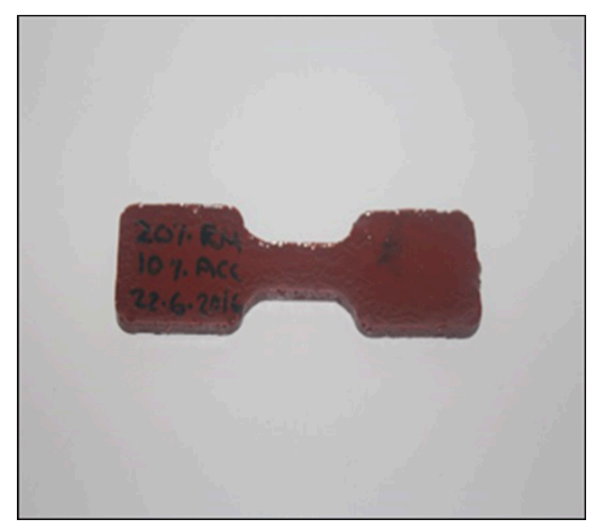

(b)

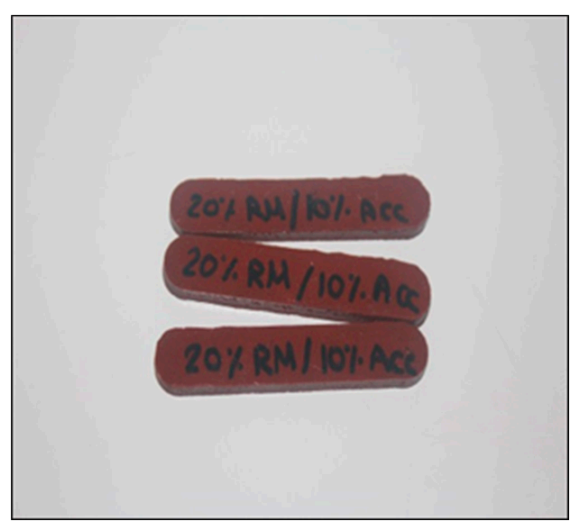

(c)

Figure 3. (a) Compression; (b) tensile; (c) flexural test samples.

\subsection{Mechanical Testing}

Universal testing machines (MTS Model MH/20 with a load capacity of $100 \mathrm{kN}$ ) were used to perform compression tests. The samples were compressed between the upper (movable) and lower (fixed) plates of the instrument. The loading persisted either until specimen fracture occurred or a predetermined minimum value was reached for the gap between the upper and lower plates. Using the same compression test machine, both the tensile and flexural curves were obtained. The sample was placed between the movable and fixed jaws of the machine. The test proceeded until sample failure occurred. All tests were performed at room temperature with an overhead speed of $2 \mathrm{~mm} / \mathrm{min}$.

\subsection{Characterization}

The morphology and microstructure of the BR particles and BR-UPR composites were investigated via scanning electron microscopy (SEM, Quanta 200 with the Inica EDX system, Hillsboro, OR, USA). The elemental compositions of MEKP and BR-UPR composites were analyzed using energy-dispersive $X$-ray spectroscopy (EDX). To ensure conductivity, all samples were sputtered with gold and the images were collected at various resolutions.

\section{Results and Discussion}

\subsection{Compression Properties}

The compression test curves for the pure polyester and composite samples are shown in Figure 4 , in which the $x$-axis represents strain and the $y$-axis represents stress. For the sake of contrast, the curve of pure unsaturated polyester is also included. Initially, stress increased as the strain increased. Then, strain softening occurred at strains between $8 \%$ and $15 \%$. The minimum stress value obtained during strain softening was $34.4 \mathrm{MPa}$. Moreover, prior to failure at $65.2 \mathrm{MPa}$ and $40 \%$ elongation, pure polyester experienced orientation hardening. The addition of BR to the polyester matrix typically decreased the orientation of the strain hardening of pure polyester. Table 3 reveals that the increase in BR content typically led to a decline in the elongation (strain\%). However, the addition of BR (up to $30 \mathrm{vol} . \%$ ) increased the elongation compared with that of pure polyester. This may be attributed to the proper transfer of stress with a slow propagation rate along the matrix as the filler (BR) content increases, thus causing the composite to break at a higher strain [22]. Additionally, this strain enhancement reflects higher BR homogeneity within the composite matrix as well as good interfacial adhesion between BR and the polyester matrix [23]. 


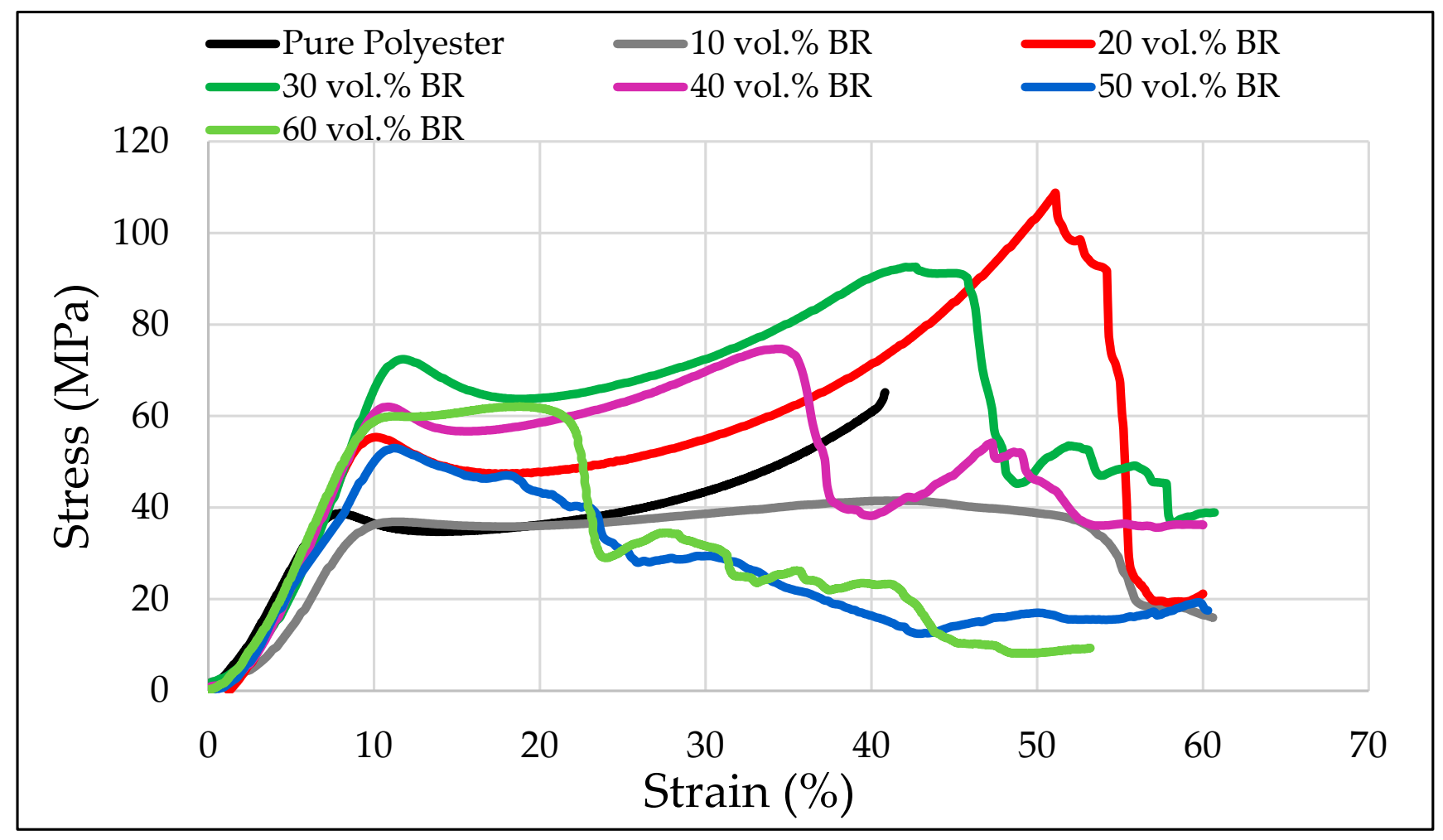

Figure 4. Compressive stress-strain curves of BR-UPR composites.

Table 3. Compressive, tensile, and flexure mechanical properties of BR-UPR composites.

\begin{tabular}{|c|c|c|c|c|c|c|c|c|}
\hline \multirow{2}{*}{$\begin{array}{c}\text { Mechanical } \\
\text { Property }\end{array}$} & \multicolumn{8}{|c|}{ BR Content (vol.\%) } \\
\hline & & 0 & 10 & 20 & 30 & 40 & 50 & 60 \\
\hline \multirow{3}{*}{ Compressive } & $\sigma_{\mathrm{f}}^{1}(\mathrm{MPa})$ & $65.2 \pm 6.7$ & $41.5 \pm 1.9$ & $108.7 \pm 1.8$ & $92.6 \pm 1.5$ & $74.7 \pm 0.6$ & $53.0 \pm 8.1$ & $62.1 \pm 0.3$ \\
\hline & $\mathrm{E}^{2}(\mathrm{GPa})$ & $0.7 \pm 0.01$ & $0.7 \pm 0.08$ & $0.8 \pm 0.03$ & $1 \pm 0.02$ & $0.9 \pm 0.004$ & $0.5 \pm 0.001$ & $0.5 \pm 0.005$ \\
\hline & Strain $(\%)$ & $40.8 \pm 0.15$ & $41.6 \pm 0.4$ & $51.2 \pm 0.2$ & $42.1 \pm 0.08$ & $34.4 \pm 0.2$ & $18.6 \pm 0.4$ & $18.8 \pm 0.6$ \\
\hline \multirow{3}{*}{ Tensile } & $\sigma_{\mathrm{f}}(\mathrm{MPa})$ & $27.6 \pm 1.3$ & $19.3 \pm 1.8$ & $13.1 \pm 0.3$ & $9.1 \pm 0.21$ & $10.5 \pm 0.13$ & $8.1 \pm 0.1$ & $4 \pm 0.23$ \\
\hline & $\mathrm{E}(\mathrm{GPa})$ & $0.9 \pm 0.02$ & $0.9 \pm 0.02$ & $1.07 \pm 0.02$ & $1.4 \pm 0.01$ & $1.2 \pm 0.01$ & $1.2 \pm 0.02$ & $0.9 \pm 0.01$ \\
\hline & Strain $(\%)$ & $4.4 \pm 0.4$ & $3.1 \pm 0.3$ & $1.8 \pm 0.1$ & $0.7 \pm 0.1$ & $1.5 \pm 0.3$ & $1.1 \pm 0.2$ & $0.4 \pm 0.1$ \\
\hline \multirow{3}{*}{ Flexure } & $\sigma_{\mathrm{f}}(\mathrm{MPa})$ & $53.3 \pm 3.7$ & $30.1 \pm 1.7$ & $23.1 \pm 1.5$ & $24.6 \pm 2.02$ & $15.5 \pm 1.7$ & $14.1 \pm 1.9$ & $23.6 \pm 1.04$ \\
\hline & $\mathrm{E}(\mathrm{GPa})$ & $24.3 \pm 0.03$ & $43.9 \pm 0.01$ & $41.3 \pm 1.2$ & $33.9 \pm 0.4$ & $23.5 \pm 0.4$ & $22.8 \pm 0.2$ & $12.3 \pm 0.3$ \\
\hline & Strain $(\%)$ & $0.6 \pm 0.04$ & $0.3 \pm 0.02$ & $0.2 \pm 0.04$ & $0.2 \pm 0.03$ & $0.2 \pm 0.02$ & $0.2 \pm 0.04$ & $0.1 \pm 0.04$ \\
\hline
\end{tabular}

${ }^{1}$ Failure strength. ${ }^{2}$ Modulus of elasticity.

The effect of BR content on the compressive strength and modulus of the composites is shown in Figure 5. The maximum compressive strength $(108.7 \mathrm{MPa})$ was reached at $20 \% \mathrm{BR}$. Initially, the adding of $10 \% \mathrm{BR}$ reduced slightly the compressive strength of the composite which can attributed to the interfering of the filler in the crosslinking process of the UPR. The compressive strength of the polyester was $65.2 \mathrm{MPa}$, indicating that the presence of $20 \%$ BR increased the compressive strength by $66 \%$. This improvement in compressive strength is due to the deposition of BR particles within the pores of the polymer matrix, which plug the pores within the polyester [24], and the presence of heavy mineral oxides in BR [8]. Above 20 vol.\% BR, the compressive strength slightly decreased with the increase in BR vol.\%. The poor interfacial bonds between the polyester and BR particles could be responsible for the slight decrease in the compressive strength of the composites above 20 vol. $\%$ BR, which in turn decreased the degree of crosslinking between BR and the polymer matrix [25]. 


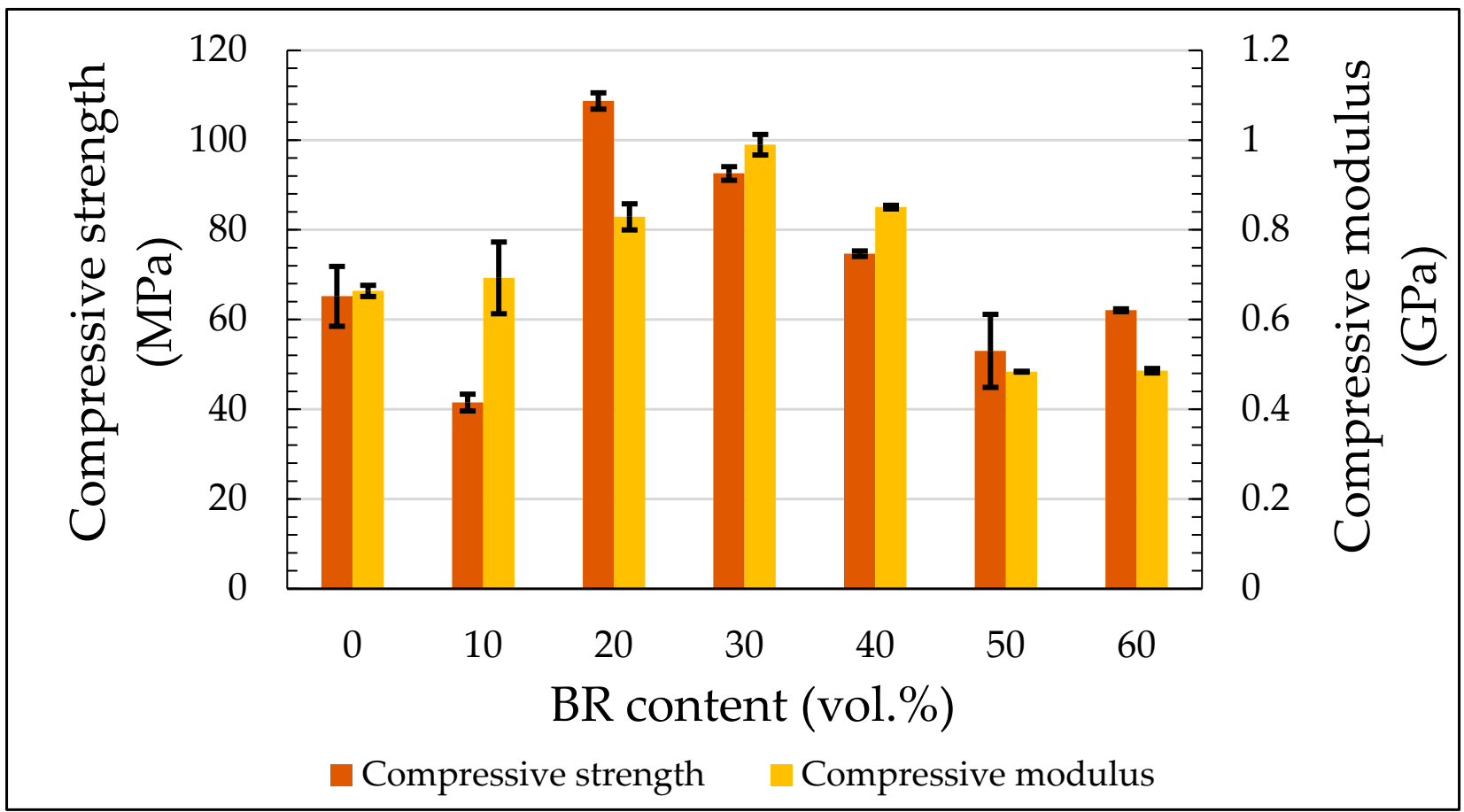

Figure 5. Effect of BR vol.\% on the composite compressive strength and modulus of BR-UPR composites.

Notably, the compressive strength at 20 vol.\% BR was $108.7 \mathrm{MPa}$, and beyond that, the compressive strengths of the prepared composites varied from 92.6 to $62.1 \mathrm{MPa}$ for 30 and 60 vol.\% BR, respectively. Nevertheless, Figure 6a shows that compared with other composites used in building walls, ceilings, and roofs, such as lightweight construction materials comprising cement, sand, and fibers of coconut and durian waste (2.4-3.3 MPa), the produced UPR-BR composites exhibited greater compressive strengths [26]. In addition, the compressive strength at 50 vol.\% BR was $53.0 \mathrm{MPa}$, which is higher than that of 50 vol.\% cement-rubber composite (10.5 MPa) reported by Benazzouk et al. [27]. Moreover, the compressive strength of the composite with $60 \mathrm{vol} . \% \mathrm{BR}(62.1 \mathrm{MPa})$ is higher than the strength of the limestone-polyester composite (50 MPa) [28] and higher than the strength of sisal-cattail hybrid-reinforced polyester composites (25 MPa) [29]. It should be also mentioned that the UPR-BR composites showed greater compressive strength compared to the traditional insulation materials used currently in construction applications like expanded polystyrene (0.035-0.414 $\mathrm{MPa})$, extruded polystyrene $(0.104-0.690 \mathrm{MPa})$ and rigid cellular polyurethane (0.104-0.414 $\mathrm{MPa})$ [30]. The addition of $\mathrm{BR}$ enhanced the compressive strength at a relatively high BR content (40 vol.\%) compared with that of the pure polyester.

As can be seen from Figure 5, the trend for the composites is different from that of pure polyester. The overall enhancement in the failure stress value of the composites can be seen in Table 3. Moreover, the elastic modulus $(E)$, which represents temporary deformation, increased with the increase in BR content up to 40 vol.\% (Figure 5). Compared with pure polyester, a $28 \%$ increase in the elastic modulus was achieved at $40 \mathrm{vol} . \% \mathrm{BR}$. The reason for this enhancement may be attributed to the fact that BR addition increases the aggregate volume of the mixture and consequently lowers the stiffness of the system [5]. 


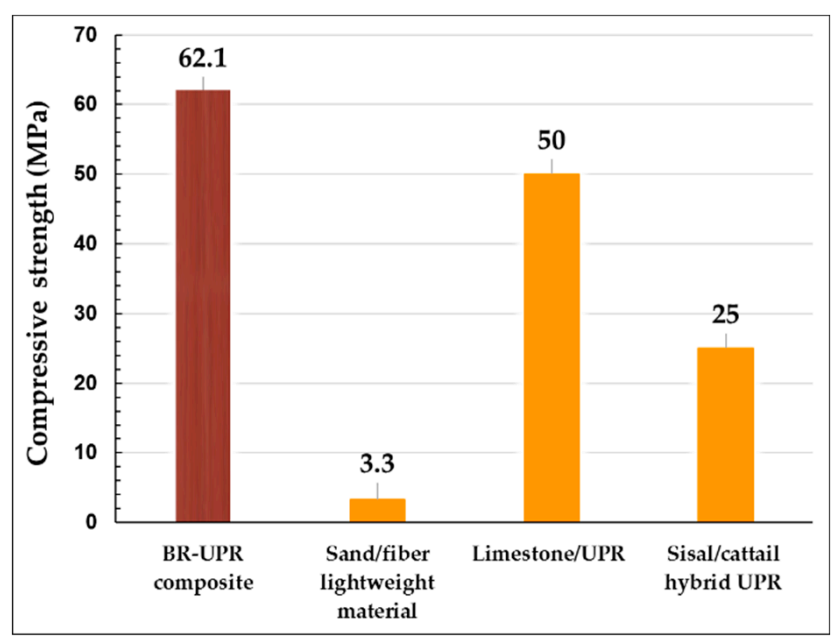

(a)

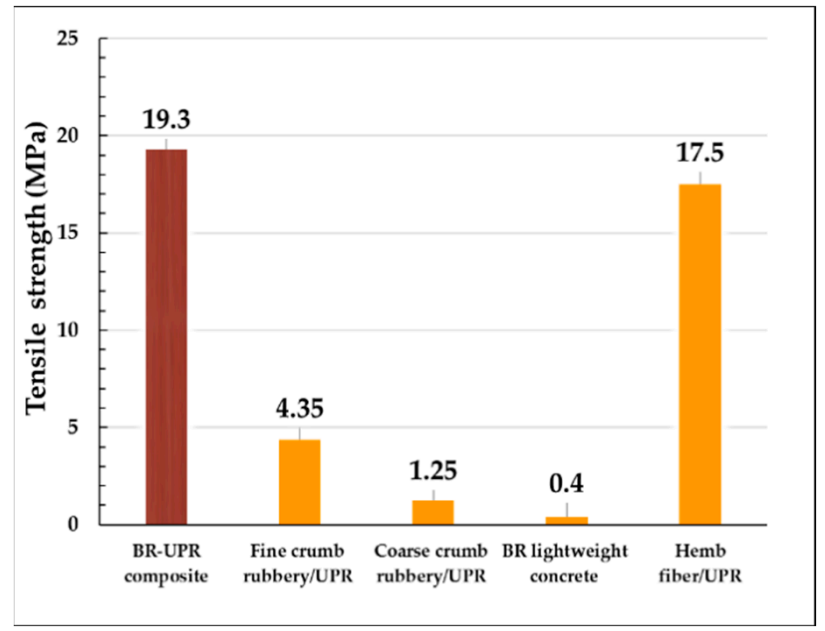

(c)

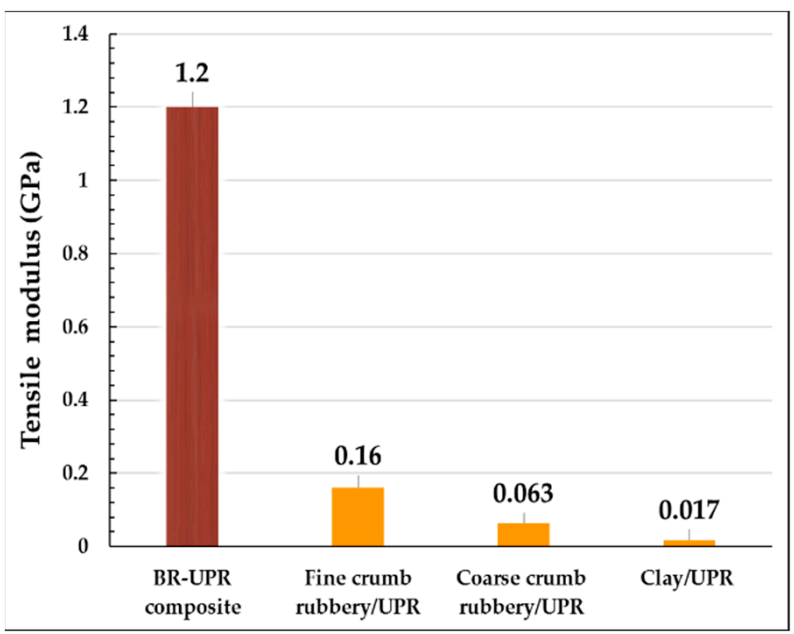

(b)

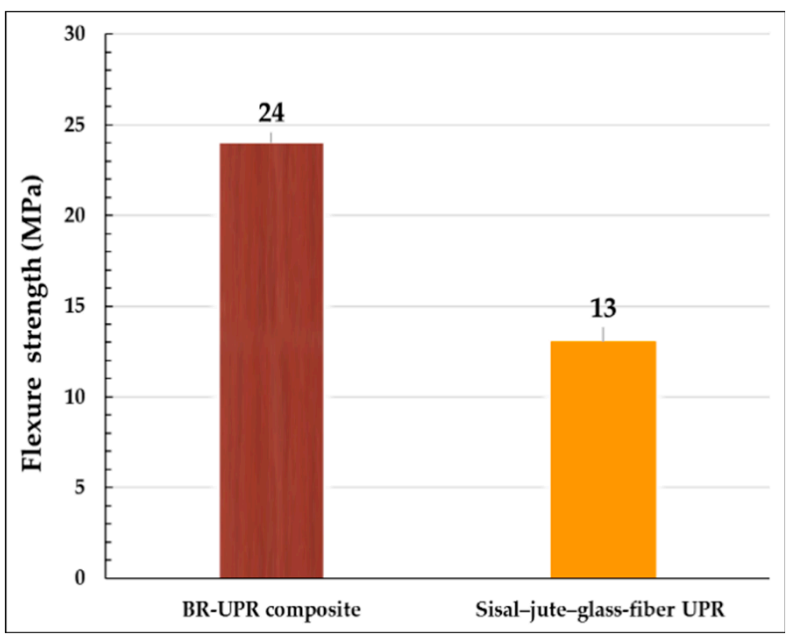

(d)

Figure 6. Mechanical properties of BR-UPR and other polyester composites (a) Compressive strength; (b) Tensile modulus; (c) Tensile strength; (d) Flexure strength.

\subsection{Tensile Properties}

The tensile stress-strain curves for the prepared samples of pure polyester and BRUPR composites are shown in Figure 7. It can be seen that the stress value of pure polyester increases almost linearly with strain, particularly in the first part of the curve. Further, for pure polyester, the elongation at break is higher than those for the composites. In addition, with increasing filler content, the linear pattern of stress-strain variation in pure polyester does not change. However, the load-bearing capacity, fracture stress, and fracture strain are reduced. This is an anticipated development as BR content increases. The same behavior was noticed by Abu-Jdayil et al. [31] for polyester scrap tire composites. The addition of BR particles seems to allow cracks to propagate, leading to a reduction in composite toughness compared with pure polyester [18].

The effects of BR content on the tensile strength, failure stress, and modulus of the composites are shown in Figure 8. It can be seen that as the BR content increases, the tensile strengths and failure stresses of the unsaturated polyester composites decrease. The maximum failure stress and elastic modulus of the neat unsaturated polyester sample were $28.85 \mathrm{MPa}$ and $0.944 \mathrm{GPa}$, respectively, whereas BR-reinforced polyester composites had 
lower failure stress values, as presented in Table 3 and Figure 8. However, a significant enhancement in the tensile modulus was observed upon the addition of BR. The reason for this improvement in the modulus of elasticity may be attributed to the fact that BR addition leads to an increase in aggregate volume in the mixture [5]. Moreover, the enhancement in tensile modulus could be due to the decrease in the viscosity of the composite with increasing BR content. Hence, fewer voids were likely produced during the fabrication process, which reduced the mechanical properties of the composites [23]. Figure $6 \mathrm{~b}$ shows that the modulus of elasticity at $40 \mathrm{vol} . \% \mathrm{BR}(1.2 \mathrm{GPa})$ is higher than or similar to the moduli of some polyester composites that have been studied for construction applications. For instance, Abu-Jdayil et al. [31] found that the moduli of elasticity at 40 vol. $\%$ fineand coarse-crumb rubbery/polyester composites were 0.16 and $0.063 \mathrm{GPa}$, respectively. Moreover, the maximum modulus of elasticity value of clay-polyester composites was reported to be $0.017 \mathrm{GPa}$, which is also lower than that of the BR-UPR composites [32]. Furthermore, it was found that the cement-stabilized base, which is the most used semirigid base material used in construction, has a modulus value of $1.36 \mathrm{GPa}$ [33]. In addition, Okonkwo et al. [34] found that the modulus of elasticity for a polyester-clay-Bambara nut shell composite was $1.3 \mathrm{GPa}$.

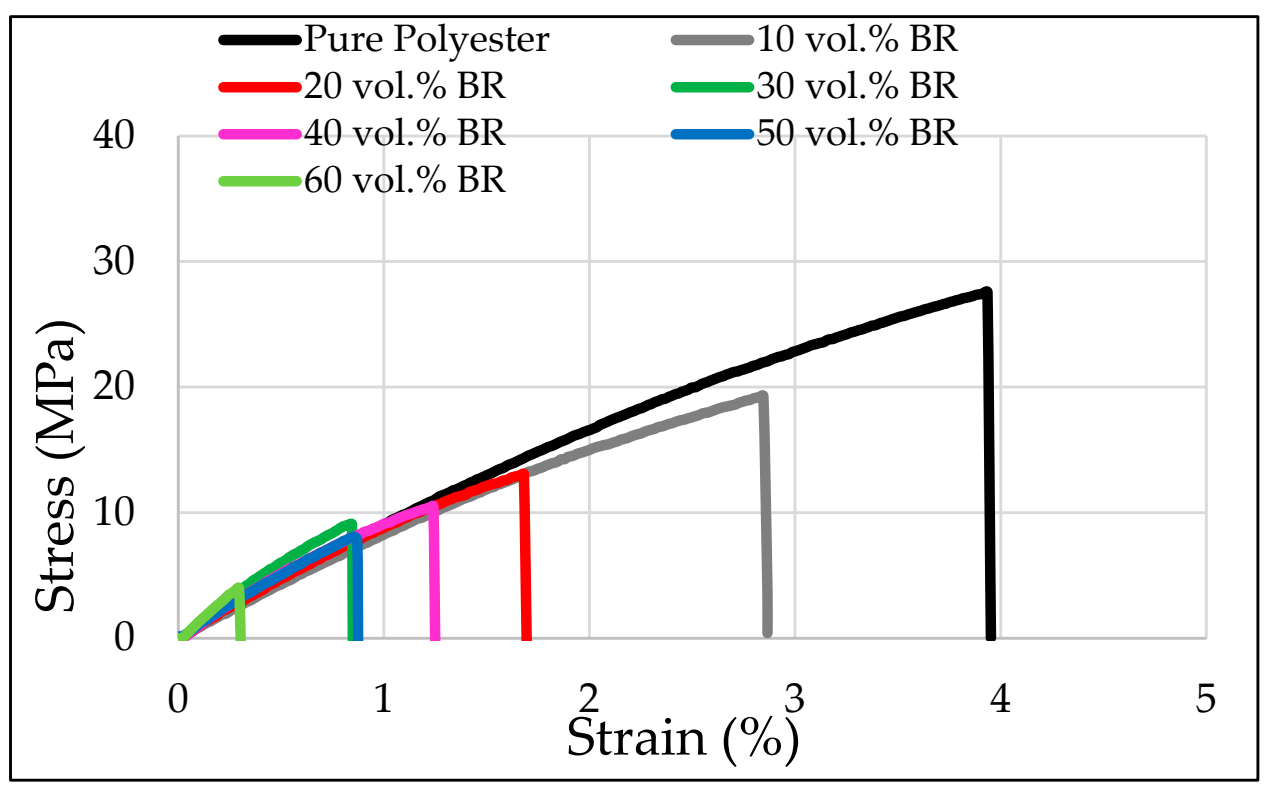

Figure 7. Tensile stress-strain curves of BR-UPR composites.

The relatively higher values of tensile strength at lower BR content can be due to strong interfacial bonding, better filler dispersion in the matrix, and lack of voids or porosity. By contrast, the reduction in tensile strength with the increase in BR content may be attributed to the lower efficiency of stress transfer between the BR particle-polyester interface due to the weak adhesion force at the interface, direct contact between particles, and the presence of voids or porosity. These were confirmed by the SEM micrographs of 20 and 60 vol.\% BR (Figure $9 \mathrm{a}, \mathrm{b}$, respectively); the BR particles were well embedded in the polyester matrix. Moreover, the degree of detachment between the filler particles and the polymer, which causes the formation of small voids or gaps, was at the minimum for $20 \mathrm{vol} . \% \mathrm{BR}$. This demonstrates the strong compatibility of BR particles with the polyester matrix reflected by the significant enhancement in tensile strength at $20 \mathrm{vol} . \%$ BR compared with that at $60 \mathrm{vol} . \%$ BR. SEM images show some kind of particles agglomeration that is expected to increase with increasing filler content. 


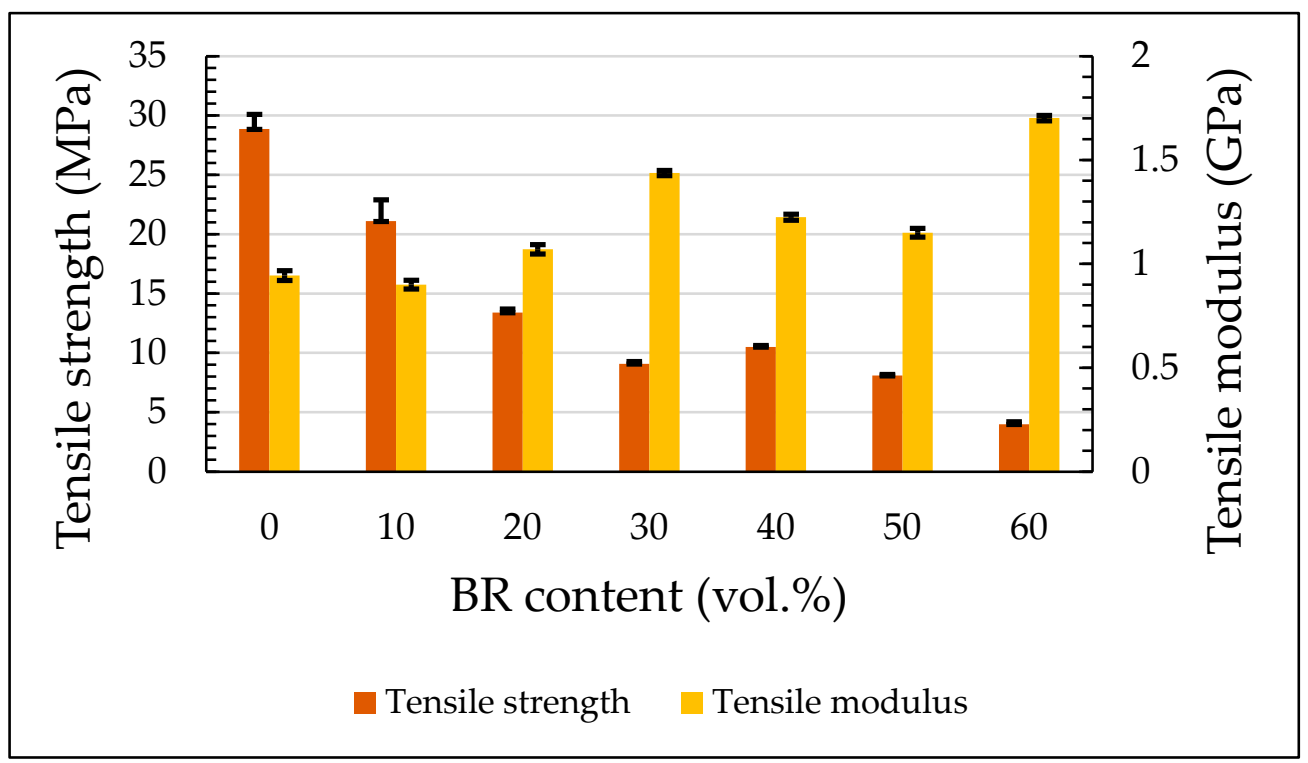

Figure 8. Effect of BR vol.\% on the tensile strength and modulus.

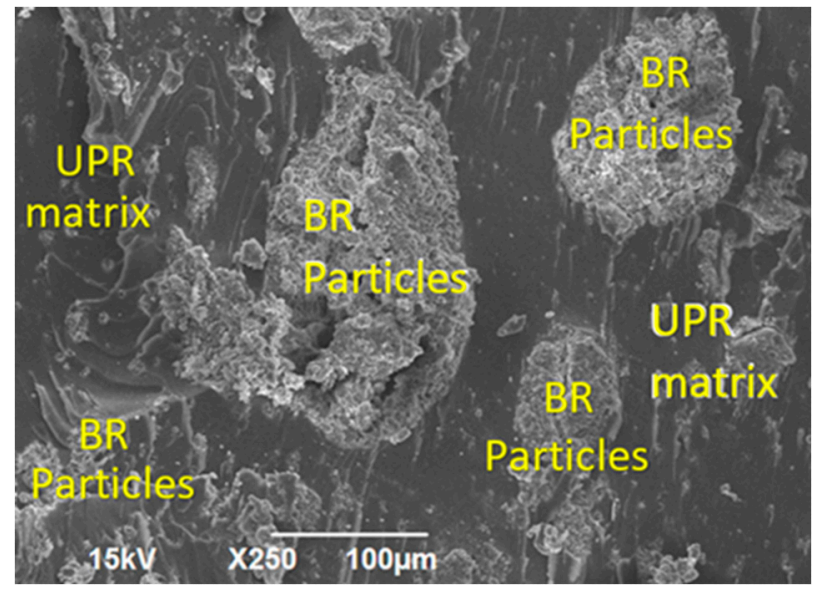

(a)

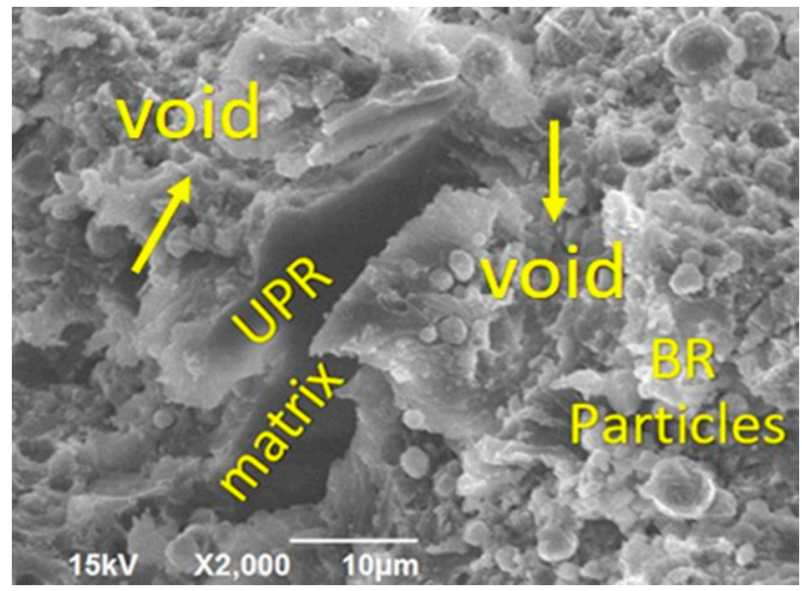

(b)

Figure 9. (a) SEM images of 20 vol.\%; (b) 60 vol.\% BR-UPR composite.

Although the tensile strength and failure stress decreased with increasing filler content, the produced composites showed outstanding tensile strengths (4.0-19.3 MPa) compared with currently used insulating materials. The reported tensile strengths for foam glass, mineral fibers, and polystyrene are $0.689,0.069$, and $0.310 \mathrm{MPa}$, respectively [35]. Moreover, Abu-Jdayil et al. [31] reported tensile strength values of 4.35 and $1.25 \mathrm{MPa}$ for $40 \mathrm{vol} . \%$ fine- and coarse-crumb rubber-polyester composites, respectively. In addition, the tensile strength value $(13.07 \mathrm{MPa})$ of the $20 \mathrm{vol} . \% \mathrm{BR}-\mathrm{UPR}$ composite is higher than that $(0.4 \mathrm{MPa})$ of the $20 \%$ BR lightweight concrete reported by Nikbin et al. (2018) [5]. Moreover, the tensile strength $(19.3 \mathrm{MPa})$ of $10 \mathrm{vol}$ \% BR-UPR is higher than that (17.5 MPa) of the hemp fiber-reinforced polyester composite reported by Neves et al. [36] (Figure 6c). The same trend can be noticed in Figure 7, where the strain decreased with increasing BR content. This strain (or elongation) decrease could be due to the defects generated by the addition of BR, which was not well distributed throughout the polyester matrix.

\subsection{Flexural Properties}

Figure 10 shows the flexural stress-strain curves for the prepared pure polyester and BR-UPR composites. Table 3 reveals that the elongation at break (strain \%) for pure polyester 
is higher than those for the BR-UPR composites. In addition, the results indicate that the load-bearing capacity, fracture stress, and fracture strain typically decrease with increasing BR content. As shown in Figure 10, the increase in BR content decreases the composite flexural strength. The same behavior was observed by Ohama et al. [37]. However, up to $30 \mathrm{vol} . \% \mathrm{BR}$, the flexural strength exhibited almost a constant value of $24 \mathrm{MPa}$. The addition of BR particles seems to allow cracks to propagate, resulting in such reduction in the composite toughness compared with that of pure polyester [37]. Nevertheless, as Figure $6 \mathrm{~d}$ shows, the presented composites with the maximum flexure strength ( $24 \mathrm{MPa})$ performed better than other types of composites, such as sisal-jute-glass-fiber-reinforced polyester composite, which had a maximum flexural strength of $13 \mathrm{MPa}$ as reported by Tang [38].

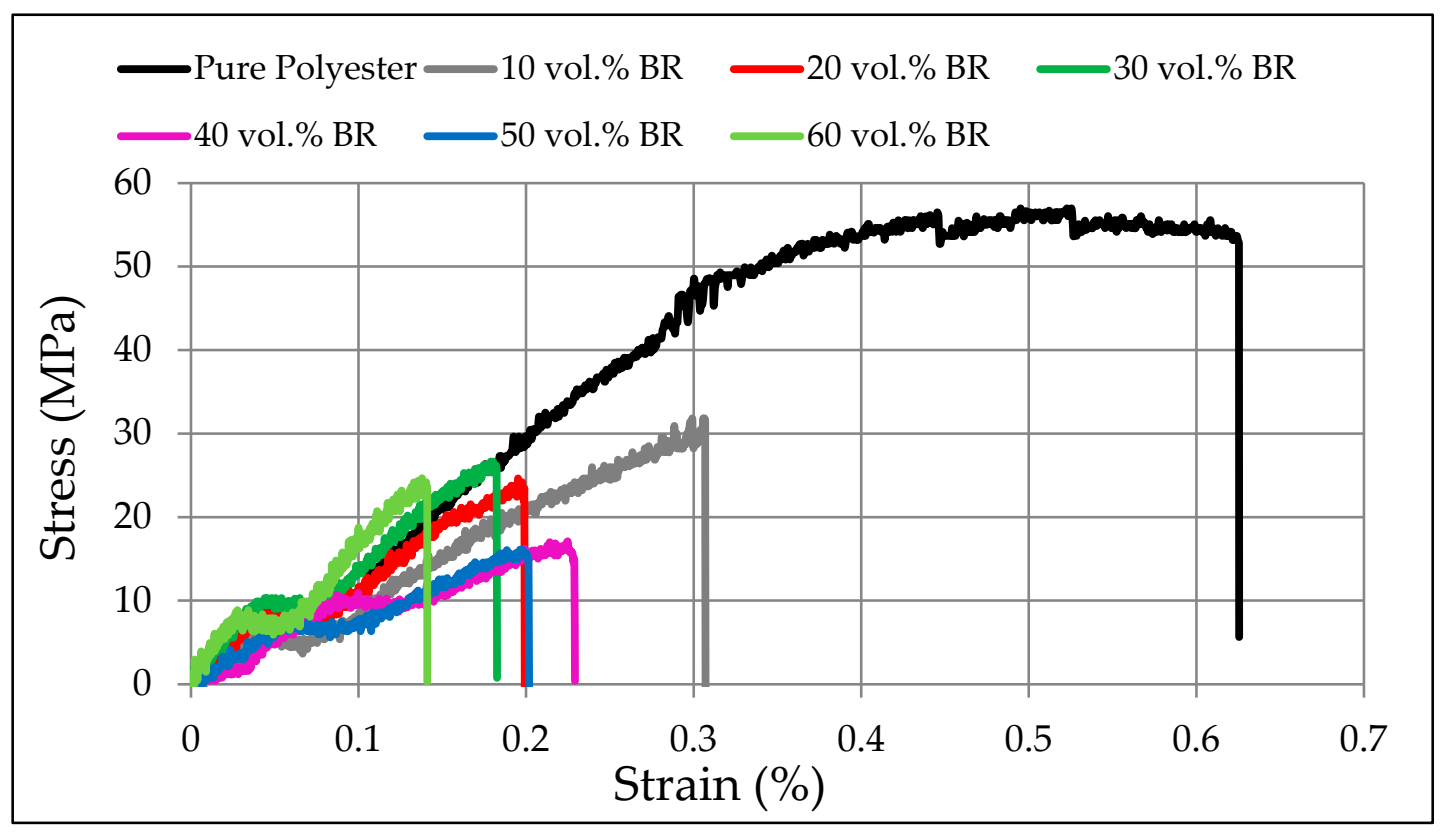

Figure 10. Flexure stress-strain curves of BR-UPR composites.

The results in Figure 11 show that adding BR to the composites results in increased modulus or stiffness compared with those of neat unsaturated polyester, as reported by Zainudin et al. [39] and Tang [38]. Nikbin et al. [5] showed the same trend for flexural strength with increased BR content as cement replacement. This behavior could be due to the inclusion of BR, which increased the rigidity of the materials [40].

\subsection{EDX Results}

Figure 12a,b and Table 4 show the surface compositions of the polyester and BR-UPR composites characterized by EDX. Figure 12a shows that the highest content is that of carbon $(\mathrm{C})$, followed by oxygen $(\mathrm{O})$, in addition to trace amounts of magnesium $(\mathrm{Mg})$ and calcium (Ca). For the BR-UPR composite (Figure 12b), the $\mathrm{C}$ and $\mathrm{O}$ contents are the highest. As can be observed from Figure $12 \mathrm{~b}$ and Table 3, besides $\mathrm{Mg}$ and a lot of $\mathrm{C}, \mathrm{O}$, considerable amounts of iron $(\mathrm{Fe})$, aluminum $(\mathrm{Al})$, silicon $(\mathrm{Si})$, and sodium $(\mathrm{Na})$ were present upon addition of $40 \mathrm{vol} . \% \mathrm{BR}$. Fe and Si tended to reduce the fracture surfaces and thereby enhance the material strength [41], which was confirmed by the higher compressive strength of the $40 \mathrm{vol} . \%$ BR-UPR composite (74.7 MPa) compared with that of pure polyester (65.2 MPa). 


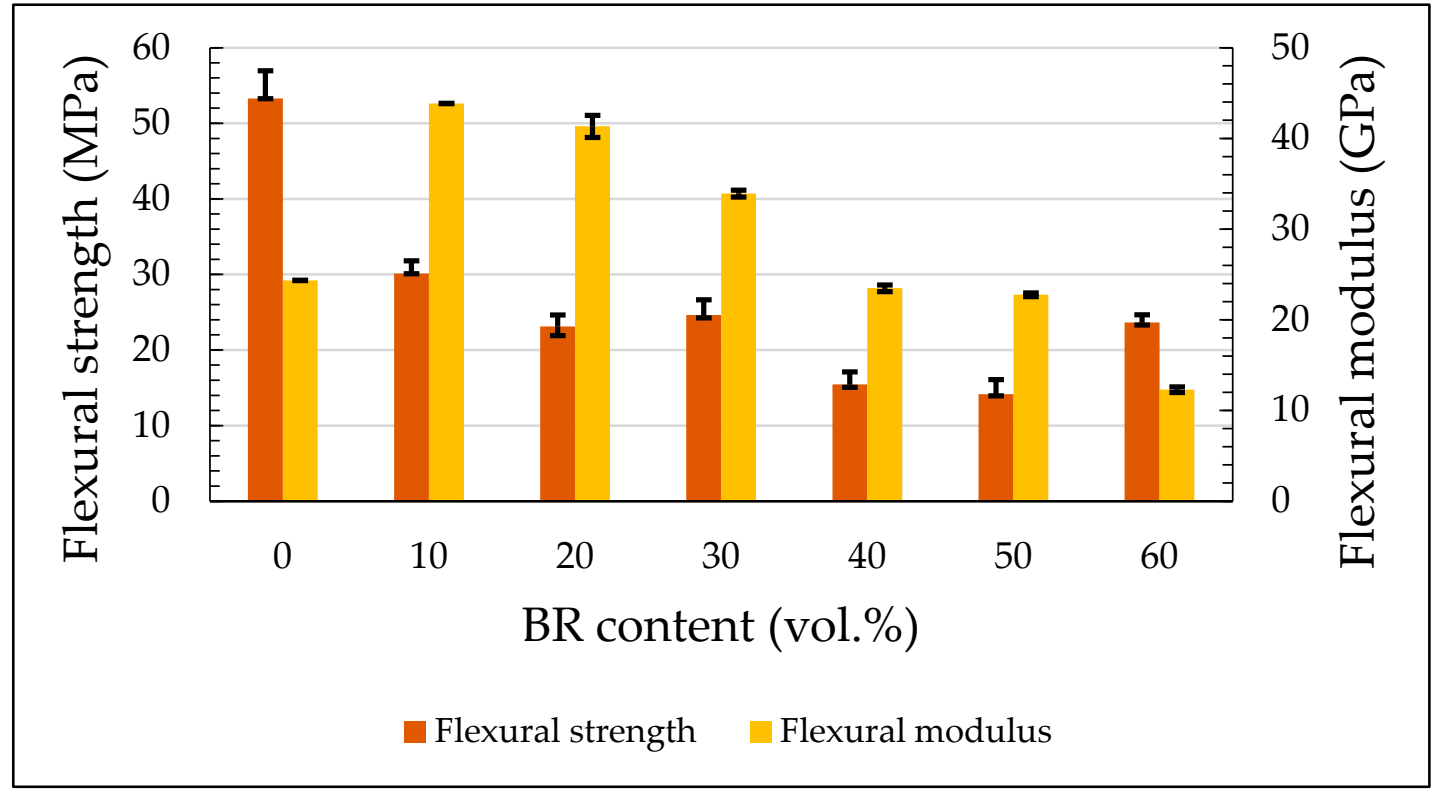

Figure 11. Effects of BR vol.\% on the flexural strength and modulus of the BR-UPR composites.

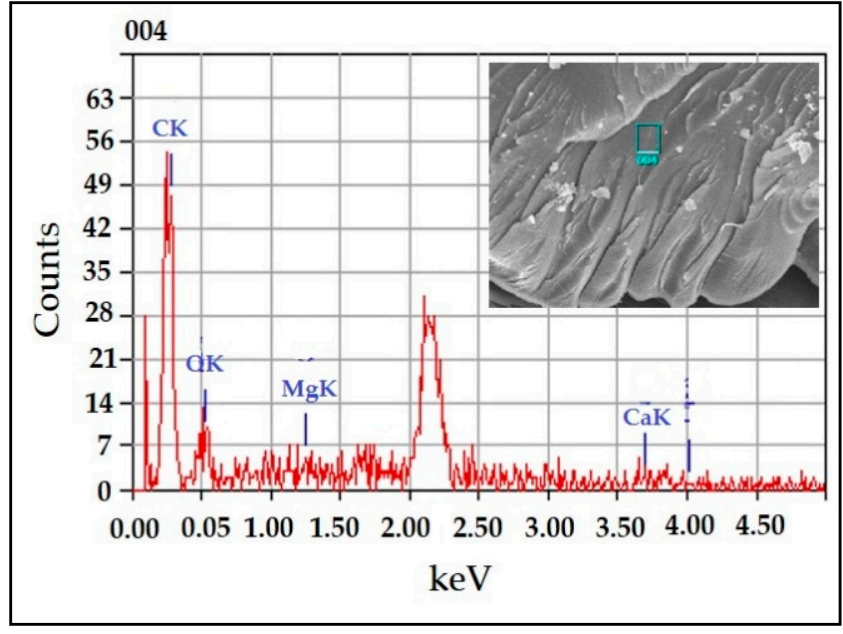

(a)

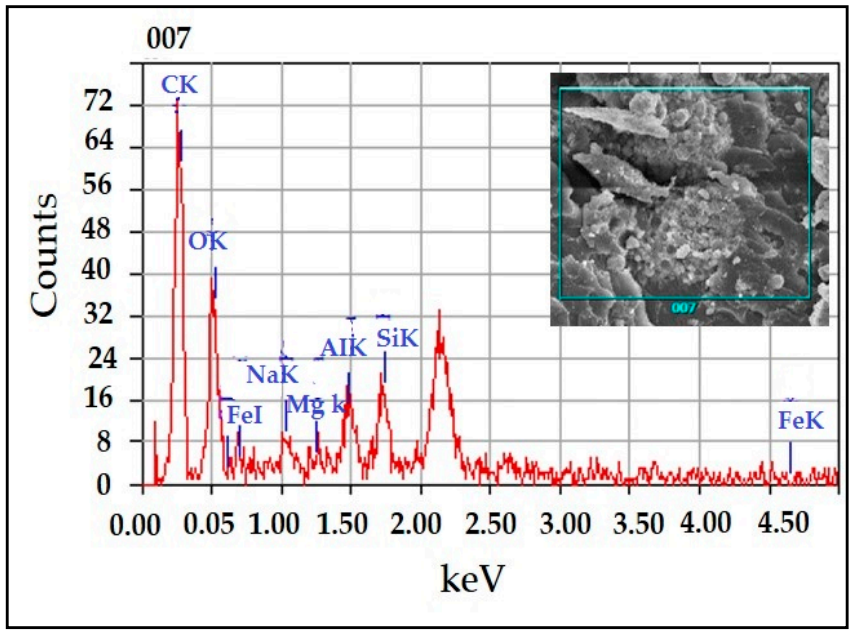

(b)

Figure 12. (a) EDX of UPR; (b) 40 vol.\% UPR-BR composite.

Table 4. EDX characteristics of polyester and BR-UPR composites.

\begin{tabular}{ccc}
\hline & \multicolumn{2}{c}{ Mass\% } \\
\cline { 2 - 3 } Element & UPR & BR-UPR Composite (40\%) \\
\cline { 2 - 3 } C K & 78.23 & 50.1 \\
O K & 18.25 & 28.28 \\
Mg K & 0.80 & 0.73 \\
Fe K & - & 10.82 \\
Al K & - & 4.02 \\
Si K & - & 4.02 \\
Na K & - & 2.03 \\
Ca K & 2.72 & - \\
Total & 100 & 100 \\
\hline
\end{tabular}




\section{Conclusions}

The mechanical test results of BR-UPR composites revealed that the addition of BR improved the compressive properties (strength, strain, and modulus) of the prepared composites. In addition, the tensile and flexural moduli exhibited significant enhancement upon the incorporation of BR in the UPR matrix. The presence of BR up to 20 vol. $\%$ increased the compressive strength of the produced composites by $67 \%$ compared with that of pure polyester. In addition to the compressive strength enhancement, the increase in strain was also observed and increased the compression toughness. This improvement in compressive strength is due to the deposition of BR particles within the pores of the polymer matrix, which plugs the pores within the polyester. EDX analysis revealed that $\mathrm{Fe}$ and $\mathrm{Si}$ tend to reduce the fracture surfaces and hence enhance the material strength [41], which was confirmed by the higher compressive strength of $40 \mathrm{vol} . \% \mathrm{BR}$ (74.7 MPa) compared to that of the polyester (65.2 MPa). Moreover, the elastic modulus, E, that represents the temporary deformation of the substance generally increased in compressive as well as tensile testing with filler contents increasing up to 40 and $60 \mathrm{vol} . \%$, respectively. The reason for this enhancement in the modulus of elasticity may be attributed to the fact that BR addition increased the aggregate volume of the mixture and consequently lowered the stiffness of the system. In contrast, the reduction in tensile and flexural strengths as the BR content increases may be attributed to the lower efficiency of stress transfer between the BR particle-polyester interface due to the weak adhesion force at the interface, direct contact between particles, and presence of void or porosity. Nevertheless, it is important to note that although the tensile strength/failure stress decreased with increasing filler content, the produced composites exhibited outstanding tensile strengths compared with currently used insulating materials. In addition, the presented composites with a maximum flexural strength of $24 \mathrm{MPa}$ performed well compared with other polyester-based composites. Moreover, incorporating BR (up to $30 \mathrm{vol} . \%$ ) with UPR increased the flexure modulus and stiffness of the BR-UPR composites compared with those of the neat unsaturated polyester owing to the insertion of BR, which increased the rigidity of the materials. Overall, the produced BR-UPR composites showed great potential for use in construction applications. The energy-saving potential of the composites can help to realize sustainable development in the field.

Author Contributions: Conceptualization, B.A.-J. and M.A.; methodology, B.A.-J., M.A., F.A.G., S.A.Y. and M.A.J.; validation, B.A.-J.; formal analysis, M.A., F.A.G., S.A.Y. and M.A.J.; investigation, M.A., F.A.G., S.A.Y. and M.A.J.; resources, B.A.-J.; data curation, M.A., F.A.G., S.A.Y. and M.A.J.; writingoriginal draft preparation, M.A. and B.A.-J.; writing-review and editing, B.A.-J.; supervision, B.A.-J.; project administration, B.A.-J.; funding acquisition, B.A.-J. All authors have read and agreed to the published version of the manuscript.

Funding: This work was supported by the Research Unit at the United Arab Emirates University (grant number SURE 31N242) and by the National Water and Energy Center at the UAE University (grant numbers 31R163).

Data Availability Statement: The data presented in this study are available on request from the corresponding author.

Conflicts of Interest: The authors declare no conflict of interest.

\section{References}

1. Tsakiridis, P.E.; Agatzini-Leonardou, S.; Oustadakis, P. Red mud addition in the raw meal for the production of Portland cement clinker. J. Hazard. Mater. 2004, 116, 103-110. [CrossRef]

2. Dodoo-Arhin, D.; Konadu, D.S.; Annan, E.; Buabeng, F.P.; Yaya, A.; Agyei-Tuffour, B. Fabrication and characterisation of Ghanaian bauxite red mud-clay composite bricks for construction applications. Am. J. Mater. Sci. 2013, 3, 110-119.

3. Power, G.; Gräfe, M.; Klauber, C. Bauxite residue issues: I. Current management, disposal and storage practices. Hydrometallurgy 2011, 108, 33-45. [CrossRef]

4. Hertel, T.; Pontikes, Y. Geopolymers, inorganic polymers, alkali-activated materials and hybrid binders from bauxite residue (red mud)-Putting things in perspective. J. Clean. Prod. 2020, 258, 120610. [CrossRef] 
5. Nikbin, I.M.; Aliaghazadeh, M.; Charkhtab, S.H.; Fathollahpour, A. Environmental impacts and mechanical properties of lightweight concrete containing bauxite residue (red mud). J. Clean. Prod. 2018, 172, 2683-2694. [CrossRef]

6. Nath, H.; Sahoo, P.; Sahoo, A. Characterization of Red Mud treated under high temperature fluidization. Powder Technol. 2015, 269, 233-239. [CrossRef]

7. Li, L.; Qian, Y.; Zhang, H.; Han, H.; Qiao, P. Synthesis of LDHs using red mud and bittern and its influence on the flame retardant properties of EVA/LDHs composites. Polym. Polym. Compos. 2020, 28, 14-25. [CrossRef]

8. Vigneshwaran, S.; Uthayakumar, M.; Arumugaprabu, V. Development and sustainability of industrial waste-based red mud hybrid composites. J. Clean. Prod. 2019, 230, 862-868. [CrossRef]

9. Manfroi, E.P.; Cheriaf, M.; Rocha, J.C. Microstructure, mineralogy and environmental evaluation of cementitious composites produced with red mud waste. Constr. Build. Mater. 2014, 67, 29-36. [CrossRef]

10. Díaz, B.; Freire, L.; Nóvoa, X.R.; Pérez, M.C. Chloride and $\mathrm{CO}_{2}$ transport in cement paste containing red mud. Cem. Concr. Compos. 2015, 62, 178-186. [CrossRef]

11. Brentner, L.B.; Eckelman, M.J.; Zimmerman, J.B. Combinatorial life cycle assessment to inform process design of industrial production of algal biodiesel. Environ. Sci. Technol. 2011, 45, 7060-7067. [CrossRef] [PubMed]

12. Joyce, P.J.; Hertel, T.; Goronovski, A.; Tkaczyk, A.H.; Pontikes, Y.; Björklund, A. Identifying hotspots of environmental impact in the development of novel inorganic polymer paving blocks from bauxite residue. Resour. Conserv. Recycl. 2018, 138, 87-98. [CrossRef]

13. Prabu, V.A.; Johnson, R.D.J.; Amuthakkannan, P.; Manikandan, V. Usage of industrial wastes as particulate composite for environment management: Hardness, tensile and impact studies. J. Environ. Chem. Eng. 2017, 5, 1289-1301. [CrossRef]

14. Rajesh, S.; Rajakarunakaran, S.; Pandian, R.S. Modeling and optimization of sliding specific wear and coefficient of friction of aluminum based red mud metal matrix composite using taguchi method and response surface methodology. Mater. Phys. Mech. 2012, 15, 150-166.

15. Liu, R.-X.; Poon, C.-S. Utilization of red mud derived from bauxite in self-compacting concrete. J. Clean. Prod. 2016, 112, 384-391. [CrossRef]

16. Ye, N.; Yang, J.; Liang, S.; Hu, Y.; Hu, J.; Xiao, B.; Huang, Q. Synthesis and strength optimization of one-part geopolymer based on red mud. Constr. Build. Mater. 2016, 111,317-325. [CrossRef]

17. Uthayakumar, M.; Manikandan, V.; Rajini, N.; Jeyaraj, P. Influence of redmud on the mechanical, damping and chemical resistance properties of banana/polyester hybrid composites. Mater. Des. 2014, 64, 270-279.

18. Fedroff, D.; Ahmad, S.; Savas, B.Z. Mechanical properties of concrete with ground waste tire rubber. Transp. Res. Rec. 1996, 1532, 66-72. [CrossRef]

19. Ganeshan, P.; Raja, K. Improvement on the Mechanical Properties of Madar Fiber Reinforced Polyester Composites. Int. J. Adv. Eng. Technol./Vol. VII/Issue II/April-June 2016, 261, 264.

20. Saradava, B.J.; Rachchh, N.V.; Misra, R.K.; Roychowdhary, D.G. Mechanical characterization of coir fiber reinforced polymer composite using red mud as filler. J. Inf. Knowl. Res. Mech. Eng. 2013, 2, 472-476.

21. Abu-Jdayil, B.; Adi, M.; Al Ghaferi, F.; Al Yahyaee, S.; Al Jabri, M. Physical and thermal insulation properties of the composites based on seawater-neutralised bauxite residue. J. Hazard. Mater. 2020, 123723.

22. Alavudeen, A.; Rajini, N.; Karthikeyan, S.; Thiruchitrambalam, M.; Venkateshwaren, N. Mechanical properties of banana/kenaf fiber-reinforced hybrid polyester composites: Effect of woven fabric and random orientation. Mater. Des. (1980-2015) 2015, 66, 246-257. [CrossRef]

23. Makki, M.S.I.; Abdelaal, M.Y.; Bellucci, S.; Abdel Salam, M. Multi-walled carbon nanotubes/unsaturated polyester composites: Mechanical and thermal properties study. Fuller. Nanotub. Carbon Nanostruct. 2014, 22, 820-833. [CrossRef]

24. Ramachandran, S.K.; Ramakrishnan, V.; Bang, S.S. Remediation of concrete using micro-organisms. ACI Mater. J. Am. Concr. Inst. 2001, 98, 3-9.

25. Topcu, I.B. The properties of rubberized concretes. Cem. Concr. Res. 1995, 25, 304-310. [CrossRef]

26. Khedari, J.; Suttisonk, B.; Pratinthong, N.; Hirunlabh, J. New lightweight composite construction materials with low thermal conductivity. Cem. Concr. Compos. 2001, 23, 65-70. [CrossRef]

27. Benazzouk, A.; Douzane, O.; Mezreb, K.; Laidoudi, B.; Quéneudec, M. Thermal conductivity of cement composites containing rubber waste particles: Experimental study and modelling. Constr. Build. Mater. 2008, 22, 573-579. [CrossRef]

28. MolaAbasi, H.; Saberian, M.; Li, J. Prediction of compressive and tensile strengths of zeolite-cemented sand using porosity and composition. Constr. Build. Mater. 2019, 202, 784-795. [CrossRef]

29. Mbeche, S.M.; Wambua, P.M.; Githinji, D.N. Mechanical Properties of Sisal/Cattail Hybrid-Reinforced Polyester Composites. Adv. Mater. Sci. Eng. 2020, 2020. [CrossRef]

30. Abu-Jdayil, B.; Mourad, A.-H.; Hittini, W.; Hassan, M.; Hameedi, S. Traditional, state-of-the-art and renewable thermal building insulation materials: An overview. Constr. Build. Mater. 2019, 214, 709-735. [CrossRef]

31. Abu-Jdayil, B.; Mourad, A.-H.I.; Hussain, A. Investigation on the mechanical behavior of polyester-scrap tire composites. Constr. Build. Mater. 2016, 127, 896-903. [CrossRef]

32. Lee, S.-R.; Park, H.-M.; Lim, H.; Kang, T.; Li, X.; Cho, W.-J.; Ha, C.-S. Microstructure, tensile properties, and biodegradability of aliphatic polyester/clay nanocomposites. Polymer 2002, 43, 2495-2500. [CrossRef] 
33. Lv, S.; Yuan, J.; Liu, C.; Wang, J.; Li, J.; Zheng, J. Investigation of the fatigue modulus decay in cement stabilized base material by considering the difference between compressive and tensile modulus. Constr. Build. Mater. 2019, 223, 491-502. [CrossRef]

34. Okonkwo, E.G.; Anabaraonye, C.N.; Daniel-Mkpume, C.C.; Egoigwe, S.V.; Okeke, P.E.; Whyte, F.G.; Okoani, A.O. Mechanical and thermomechanical properties of clay-Bambara nut shell polyester bio-composite. Int. J. Adv. Manuf. Technol. 2020, 1-14. [CrossRef]

35. Papadopoulos, A.M. State of the art in thermal insulation materials and aims for future developments. Energy Build. 2005, 37, 77-86. [CrossRef]

36. Neves, A.C.C.; Rohen, L.A.; Mantovani, D.P.; Carvalho, J.P.R.G.; Vieira, C.M.F.; Lopes, F.P.D.; Simonassi, N.T.; da Luz, F.S.; Monteiro, S.N. Comparative mechanical properties between biocomposites of Epoxy and polyester matrices reinforced by hemp fiber. J. Mater. Res. Technol. 2020, 9, 1296-1304. [CrossRef]

37. Ohama, Y.; Ramachandran, V.S. Polymer-modified mortars and concretes. In Concrete Admixtures Handbook; Elsevier: Amsterdam, The Netherlands, 1996; pp. 558-656.

38. Tang, L. Study of the Possibilities of Using Red Mud as an Additive in Concrete and Grout Mortar; Citeseer: Princeton, NJ, USA, 2014.

39. Zainudin, E.S.; Sapuan, S.M.; Abdan, K.; Mohamad, M.T.M. Mechanical properties of compression molded banana pseudo-stem filled unplasticized polyvinyl chloride (UPVC) composites. Polym. Plast. Technol. Eng. 2008, 48, 97-101. [CrossRef]

40. Luz, S.M.D.; Goncalves, A.R.; Del'Arco, A.P., Jr. Mechanical behavior and microstructural analysis of sugarcane bagasse fibers reinforced polypropylene composites. Compos. Part A Appl. Sci. Manuf. 2007, 38, 1455-1461. [CrossRef]

41. Suresh, S.; Sudhakara, D.; Vinod, B. Investigation on industrial waste eco-friendly natural fiber-reinforced polymer composites. J. Bio-Tribo-Corros. 2020, 6, 1-14. [CrossRef] 